\title{
Perancangan Aplikasi Persediaan Barang dan Bahan Makanan Menggunakan Metode FIFO pada KFC Pematangsiantar
}

\author{
Muhammad Fadly ${ }^{1}$, Dedi Suhendro ${ }^{2}$, Andriyansyah Putra ${ }^{3}$ \\ Program Studi Komputerisasi Akuntansi, AMIK Tunas Bangsa, Pematangsiantar \\ Jalan Jend. Sudirman Blok A No 1,2 dan 3 Sumatera Utara \\ Email: Muhammad123fadly@gmail.com ${ }^{1}$,dedi.su@amiktunasbangsa.ac.id ${ }^{2}$, \\ andriyan_syahputra16@yahoo.com ${ }^{3}$
}

\begin{abstract}
PT Fast Food Indonesia Tbk, Pematangsiantar Branch, methods for processing goods and food stuffs do not have adequate applications so that to monitor the expenditure of goods and foodstuffs Stock Control must check every day the amount of goods and food items that come out. Where as to make a month-end report of goods and food ingredients must count one by one the goods and food ingredients so that it requires considerable time and energy. Often the recording of goods and food supplies is in between the physical stock and computer inventory that results in losses incurred by the employees of the company. Then a system renewal is needed at PT Fast Food Indonesia Tbk, Pematangsiantar Branch. With the renewal of the system, it is expected to be able to assist in the calculation of goods and monitor the items so that at the end of the month there are no items between the physical stock and the inventory at the computer.
\end{abstract}

Keywords: Visual Basic 2010, MySQL, FIFO method

\begin{abstract}
Abstrak
Pada PT Fast Food Indonesia Tbk, Cabang Pematangsiantar, metode pengolahan barang dan bahan makanan belum terdapat aplikasi yang memadai sehingga untuk memonitoring pengeluaran barang dan bahan makanan Stok Control harus mengecek setiap hari terhadap jumlah barang dan bahan makanan yang keluar. Sedangkan untuk membuat laporan akhir bulan barang dan bahan makanan harus menghitung satu-persatu barang dan bahan makanan sehingga membutuhkan waktu dan tenaga yang cukup besar. Sering kali pencatatan persediaan barang dan bahan makanan mengalami selisih antara stok fisik dan stok opname dikomputer yang mengakibatkan kerugian yang ditanggung oleh karyawan di perusahaan tersebut. Maka dibutuhkan aplikasi di PT Fast Food Indonesia Tbk, cabang Pematangsiantar. Dengan adanya aplikasi diharapkan dapat membantu dalam perhitungan barang dan memonitoring barang tersebut sehingga pada laporan akhir bulan tidak terdapat selisi barang barang antara stok fisik dan stok opname dikomputer.
\end{abstract}

Kata Kunci: Visual Basic 2010, MySQL, metode FIFO

@ 2019 Jurnal Ilmiah MEDIA SISFO

\section{Pendahuluan}

PT Fast Food Indonesia Tbk merupakan pemegang hak waralaba tunggal untuk Kentucky Fried Chicken (KFC) di Indonesia. Perseroan memperoleh akuisisi waralaba untuk pembukaan gerai pertama kalinya di Jalan Melawai di Jakarta. Gerai pertama ini terbukti mengalami kesuksesan sehingga dibuka gerai-gerai di luar Jakarta dan ekspansi kota besar di Indonesia seperti Medan, Bandung, Semarang, Surabaya, Manado dan Makassar. Peningkatan dan pertumbuhan selama lebih dari 30 tahun menjadikan KFC tidak diragukan lagi sebagai pemimpin pasar dengan merk restoran yang cepat saji di Indonesia. Ekspansi dengan jaringan restoran yang selalu digarap agar bisa mendapatkan sentuhan dan hadir dekat dengan 
masyarakat baik kota metropolitan maupun di daerah. Sejak 4 tahun terakhir KFC memiliki fokus pada pembukaan gerai dengan tipe free standing dengan fasilitas lengkap serta jam operasional yang fleksibilitas untuk memenuhi selera konsumen.

Menu utama KFC Colonel's Original Recipe, Hot dan Crispy yang selalu menjadi menu ayam goreng paling di gemari oleh konsumen di Indonesia. Beberapa kategori menu KFC antara lain menu Goceng, menu praktis dan menu paket kombinasi dengan harga terjangkau bernilai tambah, super panas dan KFC attack. Menu pelengkap nya disajikan juga produk sesuai dengan selera lokal diantara nya: Nasi, salad, perkedel serta soup KFC yang bertipe free standing sedangkan produk kopi berkualitas baik panas atau dingin disajikan pada counter yang terpisah untuk para penikmat kopi.

KFC selalu memonitoring kualitas di pasar dan pecinta guna mendapat tanggapan dan respon tentang produk, layanan serta fasilitas yang disebut sebagai Brand Image Tracking Study (BITS). Hal ini untuk mengetahui persepsi konsumen terhadap citra, pelayanan, fasilitas serta kualitas dari menu yang disajikan oleh KFC sebagai restoran cepat saji. Oleh karena itu dalam pengolahan data barang dan bahan sudah menjadi kebutuhan utama untuk menjalankan aktivitas dan laporan di tiap-tiap bagian di PT Fast Food Indonesia Tbk. Oleh karena itu diperlukan pengolahan dan pengawasan yang baik agar tidak terjadi kekurangan persediaan yang dapat mengakibatkan aktivitas perusahaan tersebut terganggu.

Adanya persediaan yang cukup untuk melayani permintaan pelanggan atau untuk keperluan produksi, merupakan faktor yang sangat penting untuk mempertahankan kelangsungan usaha perusahaan tersebut. Jika terjadi penumpukan persedian dalam jumlah yang berlebihan yang disebabkan oleh buruknya perputaran persediaan akan menimbulkan resiko dalam penyediaan dana atau modal kerja, peningkatan biaya penyimpanan, biaya pemeliharaan, biaya kesempatan dan resiko kerusakan persediaan.

Pada KFC kota Pematangsiantar dalam mengelola sistem barang dan bahan makanan menggunakan Sistem First in First out (FIFO) yang dijalankan secara manual, sehingga sering terjadi selisih antara stok fisik dan stok opname dan Sistem FIFO tersebut pada perhitungan akhir bulan stok fisik barang dan bahan makanan yang ada dengan stok opname di komputer sering selisih karena pengambilan yang manual, sehingga setiap bulannya perlu dilakukan pengentrian data ulang.

Selama melaksanakan penelitian penulis mengamati segala kekurangan yang ada pada program tersebut. karena pada Sistem perhitungan barang dan bahan makanan banyak kekurangan maka masih perlu dilakukan pembaharuan dan perbaikan agar mendapatkan hasil yang lebih efektif dan efisien.

Oleh karena itu, untuk menunjang kinerja dalam pendataan barang dan bahan makanan serta pembuatan laporan bulanan maka perusahaan membutuhkan sebuah pengembangan dari sistem informasi persediaan barang yang memiliki fungsi yang sama namun ditambah dengan sistem monitoring persediaan barang untuk menyakinkan dan menyesuaikan bahwa persediaan barang tersebut ada dan sesuai dengan keadaan fisiknya, sedangkan metode penilaian yang digunakan adalah metode FIFO, dimana dalam metode ini barang yang pertama masuk yang pertama keluar. Dari rumusan masalah diatas, maka dilakukan suatu penelitian yang bertujuan untuk mengembangkan sistem Informasi Persediaan Barang Pada PT Fast Food Indonesia Tbk Cabang Pematang siantar.

\section{Tinjauan Pustaka}

Masalah yang dihadapi perusahaan saat ini adalah sistem pengendalian internal yang kurang baik dalam prosedur pengelolahan persediaan di mana terdapat dokumen pendukung yang kuat atas transaksi yang terjadi seperti Faktur Pemasok, Bukti Pengiriman Pemasok (Surat Jalan), Bukti pengeluaran kas (Bukti Transfer, Cek) namun tidak adanya aplikasi prosedur pengambilan barang dan bahan makanan bermetode FIFO sehingga mengakibatkan terjadi ketidaksesuaian pencatatan persediaan dengan bukti fisik persediaan yang ada [1]. Oleh karena itu perlu untuk mengusulkan solusi perubahan terhadap sistem baru yang memenuhi seluruh kriteria pengendalian internal yang baik pada perusahaan. Analisis dilakukan dengan pengamatan proses bisnis dan pengumpulan data perusahaan dan mengusulkansolusi untuk mengatasi permasalahan.

Dalam perancangan dibuat suatu alur kerja terkomputerisasi yang telah melalui proses perancangan komponen model, komponen fungsi dan database. Penerapan sistem pengembangan yang diusulkan 
memberikan manfaat dalam meningkatkan kinerja perusahaan sehingga berbagai kesalahan dan masalah yang sebelumnya sering terjadi dapat diatasi. Selain itu sistem informasi akuntansi yang dirancang berfungsi memberikan informasi stok barang dan bahan makanan (laporan) yang dibutuhkan pihak manajemen untuk melakukan evaluasi kinerja perusahaan dan membuat kebijakan serta menyusun strategi untuk pengembangan perusahaan. Kinerja Perusahaan merupakan faktor yang menjadi perhatian untuk bisa menjaga kelangsungan dan bertahan hidup nya suatu perusahan karena kinerja persediaan salah satu bagian dari prestasi kinerja perusahaan dalam menjalankan operasionalnya, baik pemasaran, teknologi, keuangan dan sumber daya manusia [2].

Database adalah suatu kelompok informasi yang terkait dalam suatu system pengelolahan data sehingga menghasikan suatu informasi yang cepat dan benar. Dalam hal ini database merupakan alat yang membantu pengarsipan dengan cara komputerisasi, sehingga tempat, waktu dan biaya lebih hemat, karena file-file yang diarsipkan dapat discan dan kemudian dapat disimpan di komputer, dengan menggunakan source pada unit Program Studi Administrasi Bisnis [3].

Penyusunan laporan keuangan pada umumnya menyediakan informasi yang berkaitan dengan posisi keuangan atau hasil usaha dalam perusahaan serta perubahan posisi keuangan suatu perusahaan yang bermanfaat bagi pemakai dalam pengambilan keputusan ekonomi sehingga tujuan laporan keuangan memberikan informasi keuangan suatu perusahaan, baik pada saat tertentu maupun pada periode tertentu, yang disusun secara mendadak maupun secara berkala, serta mampu memberikan informasi keuangan kepada pihak dalam dan luar perusahaan yang memiliki kepentingan terhadap perusahaan [4].

Dalam pengelolaan data transaksi khususnya untuk transaksi penjualan secara kredit masih dilakukan dengan manual yaitu dengan cara mencatat seluruh transaksi kedalam buku besar. Informasi akuntansi merupakan data penting berupa laporan keuangan yang dibuat oleh suatu entitas atau organisasi dan memiliki manfaat untuk memberi pemahaman mengenai posisi keuangan dan seluruh transaksi yang dilakukan oleh suatu entitas pelaporan selama satu periode pelaporan [5]. Kegiatan manusia dalam memenuhi kebutuhannya menyebabkan mereka perlu bergerak dan saling berhubungan [6]. Pada era digital sekarang ini, internet merupakan salah satu kebutuhan pokok manusia. Berbagai aspek kehidupan tidak terlepas dari keberadaan internet. Berdasarkan survey yang dilakukan emarketer, diperkirakan pada tahun 2017 Indonesia menempati ranking ke-6 di dunia untuk pengguna internet terbanyak, yaitu sejumlah 112,6 juta pengguna internet, dan pada tahun 2018 diperkirakan akan meningkat menjadi 123 juta [7].

Persediaan merupakan suatu aktiva yang meliputi barang dan bahan makanan milik perusahaan dengan maksud untuk dijual dalam suatu masa tertentu, atau persediaan barang dan bahan makanan yang masih dalam masa taruhnya.

Jenis - jenis persediaan menurut fungsinya

1. Batch Stock/Lot Size Inventory Persediaan yang diadakan karena kita membeli atau membuat bahan makanan atau barang dalam jumlah yang lebih besar dari pada jumlah yang dibutuhkan saat itu. Biasanya bara ng ini digunakan pada saat tertentu saja misalnya ada pesanan dalam jumblah besar.

2. Fluctuation Stock Persediaan yang diadakan untuk menghadapi fluktuasi permintaan konsumen yang tidak dapat diramalkan. Barang atau bahan makanan ini permintaanya dalam semiunggu sekali atau kurang dalam seminggu karna permintaan yang fluktuasi tersebut.

3. Anticipation Stock Persediaam yang diadakan untuk menghadapi fluktuasi permintaan yang dapat diramalkan, berdasarkan pola musiman yang terdapat dalam satu tahun dan untuk menghadapi penggunaan, penjualan, atau permintaan yang mningkat. Biasanya permintaan ini ada pada bulan awal yaitu bulan februari, maret dan april [8] .

Barang dan bahan makanan adalah produk utama yang dijual KFC dengan pengolahan yang bagus maka diharapkan tidak ada selisi antara stok opname dan stok fisik barang dan bahan makanan Setiap melakukan pembelian ke produsen, setelah itu stok control akan melakukan pengentrian barang ulang dengan menambah barang yang masuk dengan barang yang sudah ada. Sistem pencatatan yamg dilakukan oleh seorang stock control membutuhkan waktu yang cukup lama untuk mengentri barang satu persatu dan metode yang dilakukan oleh KFC Pematang siantar adalah Metode FIFO (first in first out) yaitu barang atau bahan yang memiliki tanggal lebih awal dalam kadaluarsa merupakan barang atau bahan 


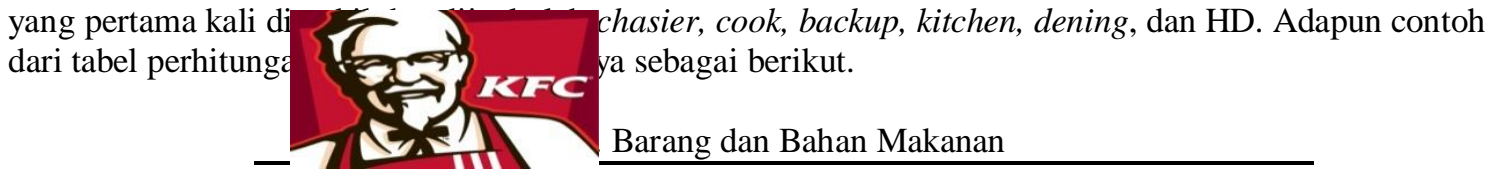
KFC PEMATANGSIANTAR
JL DR. SUTOMO NO.24 A,B,C PEMATANGSIANTAR

\begin{tabular}{|c|c|c|}
\hline $\mathrm{NO}$ & NO.ITEM & NAMA BARANG \\
\hline 1 & $30-2110$ & OR BURGER \\
\hline 2 & $30-8005$ & FISH FILLET \\
\hline 3 & $30-8006$ & TWISTY \\
\hline 4 & $30-8007$ & CHICKEN FILLET \\
\hline 5 & $30-8008$ & CHICKEN CHEEZ \\
\hline 6 & $30-8010$ & FRENCH FRIES L \\
\hline 7 & $30-9220$ & FRENCH FRIES R \\
\hline 8 & $30-9222$ & SPAGHETTY \\
\hline 9 & $30-9223$ & BURGER DELUXE \\
\hline 10 & $30-9224$ & CHICKEN SOUP \\
\hline 11 & $30-9225$ & CREAM SOUP \\
\hline 12 & $30-9227$ & DRINK \\
\hline 13 & $30-9229$ & PEPSI / 7 UP / MIRINDA M \\
\hline 14 & $30-9230$ & PEPSI / 7 UP / MIRINDA R \\
\hline 15 & $30-9233$ & MOCCA FLOAT (CUP 16) \\
\hline 16 & $30-9234$ & LYCHEE FLOAT (CUP 16) \\
\hline 17 & $30-9235$ & MANGGO FLOAT (CUP 16) \\
\hline 18 & $30-9236$ & TROPICAL FLOAT (CUP 16) \\
\hline 19 & $30-9237$ & AIR MINERAL \\
\hline 20 & $30-9231$ & ICHI OCHA \\
\hline 21 & $35-1070$ & OVALTINE TENTRA \\
\hline 22 & $35-1073$ & PERKEDEL \\
\hline 23 & $35-1074$ & BUBUR KFC ( 14 PCK X 425 GRM/CTN ) \\
\hline 24 & $35-1075$ & BERAS (25PCKX2KG/BAL) \\
\hline 25 & $35-1080$ & VLA PUDING KFC 12X250GRM/CTN \\
\hline 26 & $35-1083$ & PUDING COKLAT KFC 12X500GRM/CTN \\
\hline 27 & $35-1084$ & SAYURAN KALENGAN WORTEL (24TIN) \\
\hline 28 & $35-2128$ & TEPUNG TERIGU, 25KG/SACK \\
\hline 29 & $35-2132$ & HOT SPICY BREADING MIX,48x198 GRM \\
\hline 30 & $35-2135$ & JAGUNG KALENG \\
\hline 31 & $35-2136$ & WORTEL KALENG \\
\hline 32 & $35-2137$ & SAMBAL SASET 500 GRM \\
\hline 33 & $35-3176$ & TOMAT SASET 500 GRM \\
\hline 34 & $35-3198$ & SAMBAL POCH 1 KGS \\
\hline 35 & $35-3199$ & TOMAT POCH 1 KGS \\
\hline 36 & $35-3200$ & COPY SASET \\
\hline 37 & $35-3207$ & CUP ES CREAM 12 CUP \\
\hline 38 & $35-3208$ & MINYAK NABATI \\
\hline 39 & $35-3209$ & SAUCE SPAGETY 1 CTN \\
\hline 40 & $35-3210$ & BBQ SAUCE 500 CTN \\
\hline 41 & $35-3211$ & O-MAYO 10 GRM \\
\hline 42 & $35-3212$ & TAR-TAR 10 GRM \\
\hline 43 & $35-3213$ & CUP 12 POLOS \\
\hline 44 & $35-3214$ & CUP 12 CRUSER LOGO \\
\hline 45 & $35-3215$ & CUP HOT 12 \\
\hline 46 & $35-4002$ & CUP PUDING MINI 150 ML \\
\hline 47 & $35-4003$ & CUP IP 120 LOGO KFC \\
\hline
\end{tabular}




\begin{tabular}{lll}
48 & $35-4004$ & CUP PORIDGE BREAKFAST \\
49 & $35-4007$ & BAHAN KFC SUP \\
50 & $35-4008$ & BAHAN SALAD 12 POD \\
\hline
\end{tabular}

Metode akuntansi FIFO dan LIFO merupakan sarana pengelolaan persediaan dan masalah keuangan perusahaan yang berkaitan dengan persediaan barang dan bahan makanan yang dihasilkan. FIFO merupakan singkatan dari First in first out atau dalam bahasa indonesia, Pertama masuk pertama keluar itulah yang dicatat sebagai barang yang dijual sedangkan LIFO merupakan singkatan dari Last In First Out, atau dalam bahasa indonesia, Terakhir masuk pertama keluar yang berarti bahwa persediaan yang terakhir masuk adalah barang yang pertama kali dicatat sebagai barang yang dijual. Dalam Metode First In First Out perhitungan harga pokok didasarkan atas urutan pembelian barang tersebut. Dengan demikian, persediaan yang tertinggal atau persediaan sisa dianggap berasal dari waktu pembelian terakhir

Barang pertama masuk atau dibeli menjadi barang yang pertama keluar atau dijual. Pertama masuk pertama keluar dalam arti persediaan perolehan awal masuk akan dijual atau digunakan terlebih dahulu, sehingga persediaan akhir dinilai dengan nilai perolehanpersediaan yang terakhir masuk atau terakhir dibeli. Metode ini cenderung menghasilkan persediaan yang nilainya tinggi dan berdampak pada nilai aktiva perusahaan yang dibeli. Metode FIFO merupakan metode penilaian persediaan yang sangat realistis dan cocok digunakan untuk semua sifat produk. Realistisnya terletak pada barang yang pertama kali dibeli, maka barang itulah yang pertama kali dijual. Jika perusahaan menggunakan metode FIFO dalam menilai persediaan dengan asumsi telah terjadi peningkatan harga barang atau inflasi [9].

\section{Metodologi}

Adalah tahap pengambilan data langsung dari sumber yang diteliti. Ada beberapa tahap atau metode yang penulis buat diantaranya:

1. Observasi Lapangan

Pada metode ini lebih melakukan pendekatan kepada pihak terkait yang berhubungan dengan aplikasi ini, yaitu Ship Leader yang mengerti hubungan Komputerisasi Akuntansi. Kemudiaan melakukan pengumpulan jurnal - jurnal yang ada untuk di jurusan untuk dilakukan pengecekan.

2. Observasi Kepustakaan

Metode penelitian dengan kepustakaan adalah merupakam metode mencari beberapa materi serta keterkaitan data ataupun perbandingan jurnal yang telah membahas kajian yang sama dengan tema penelitian ini. Biasanya kepustakaan disini lebih kesisi pengembangan sistem yang akan dibuat user interface yang cocok dengan bahan kajian. Sehingga pada saat mengalami masalah kesulitan dalam mengembangkan masalah, dapat terpecahkan dengan beberapa studi pustaka diatas.

3. Wawancara

Wawancara Penulis melakukan tanya jawab langsung kepada pihak-pihak yang terkait yaitu Manager, kepala gudang PT. Fast Food Indonesia Tbk, administrasi gudang, bagian marketing dan bagian purchasing mengenai sistem dan prosedur keluar masuk persediaan barang menggunakan metode FIFO pada PT Fast Food Indonesia Tbk [10].

\section{Hasil Dan Pembahasan}

4.1 Rancangan DFD

Aliran data dalam suatu sistem informasi harus dirancang sedemikian rupa agar informasi yang dihasilkan sesuai kebutuhan informasi dari pengguna sistem. DFD digunakan untuk menampilkan rancangan aliran data dalam suatu sistem informasi berikut ditampilkan DFD level 0 dan DFD level 1 adalah sebagai berikut; 


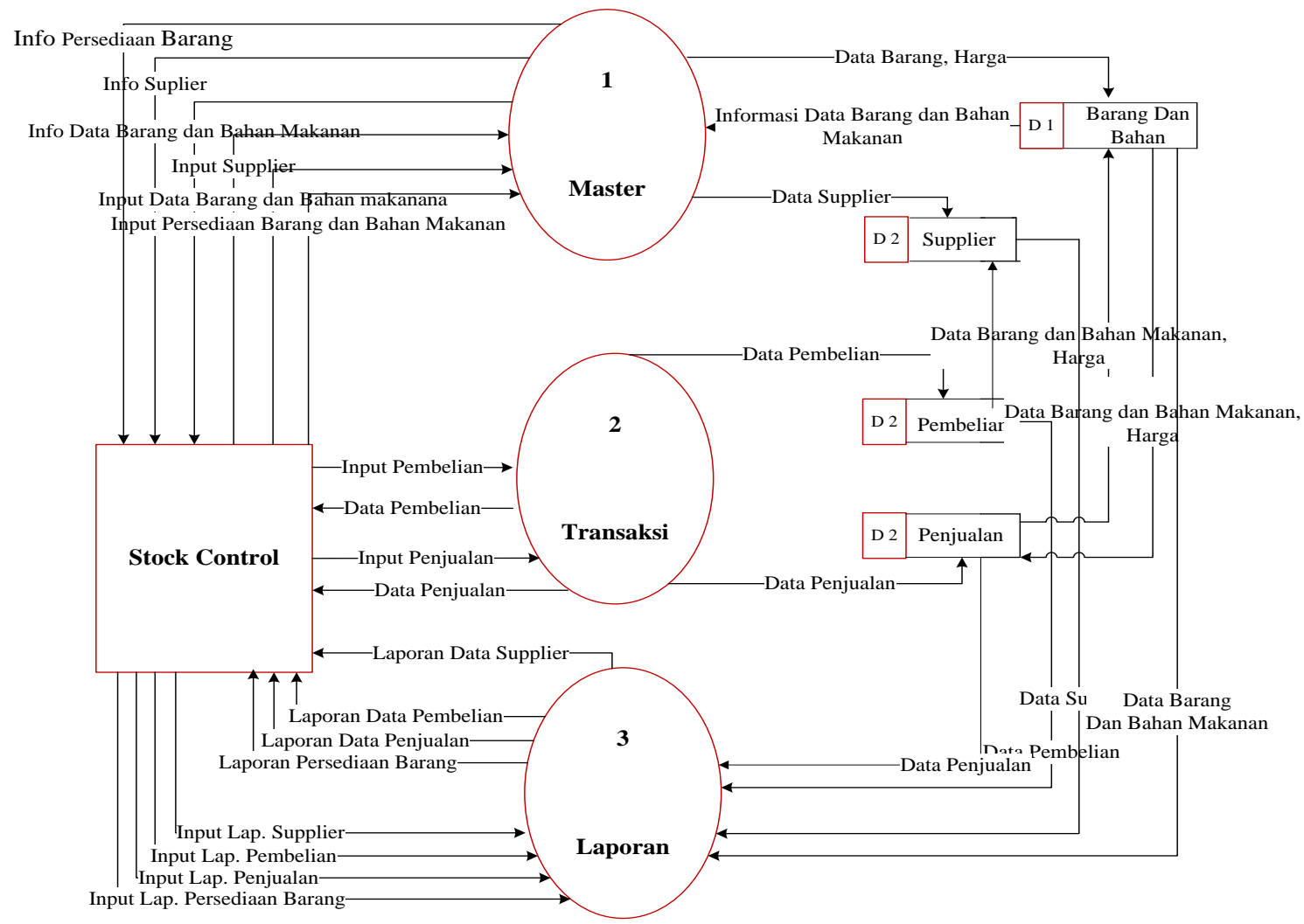

Gambar 1. DFD Level 0

Menu master berisi tentang data yang telah ada, dan dari menu master akan dilanjutkan ke transaksi dimana dengan bertambahnya transaksi maka otomatis stock kontrol berkurang namun bertambah ke data pembelian dan penjualan. Setelah semua transaksi telah selesai maka akan memasuki tahap pencetakan laporan. Pencetakan laporan akan diberikan kepada manager.

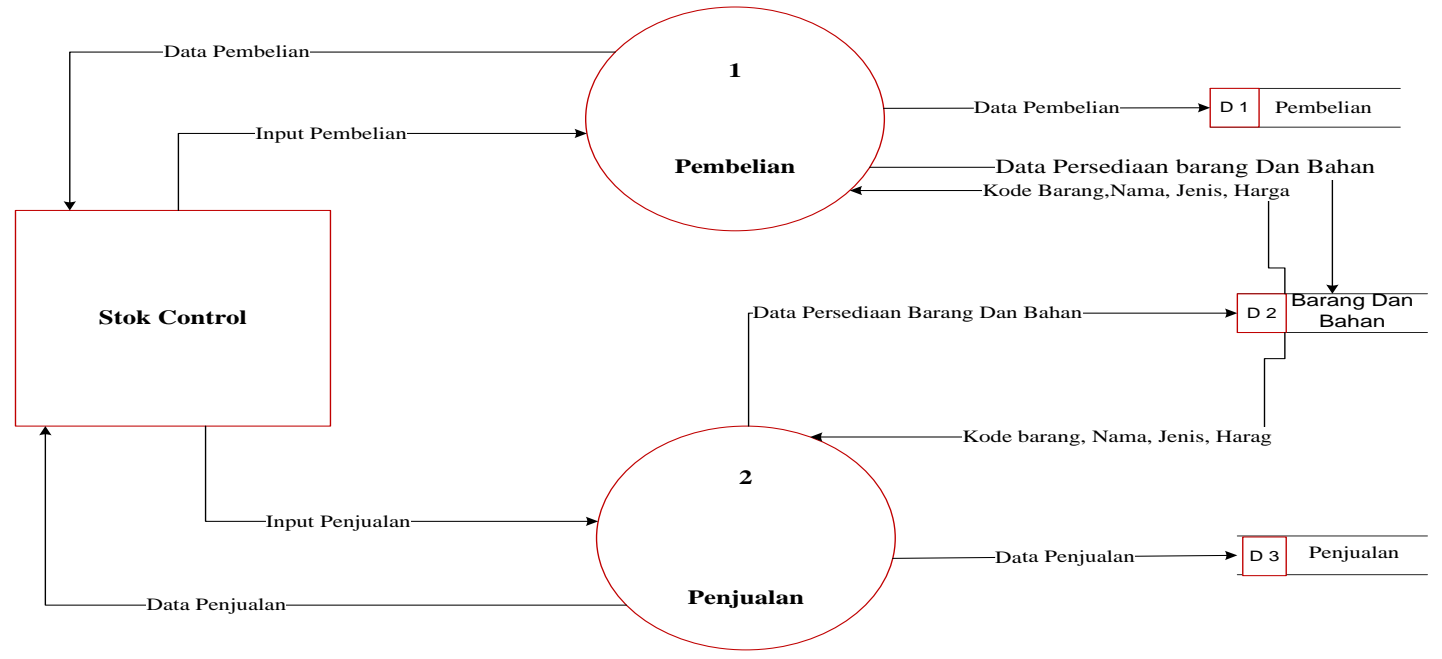

Gambar 2. DFD Level 1 transaksi

Gambar diatas menjelaskan bahwa transaksi pembelian dan penjualan berhubungan dengan stock kontrol. Jika terjadi pembelian maka stock kontrol otomatisa bertambah dan jika terjadi penjualan maka stok kontrol otomatis berkurang. 


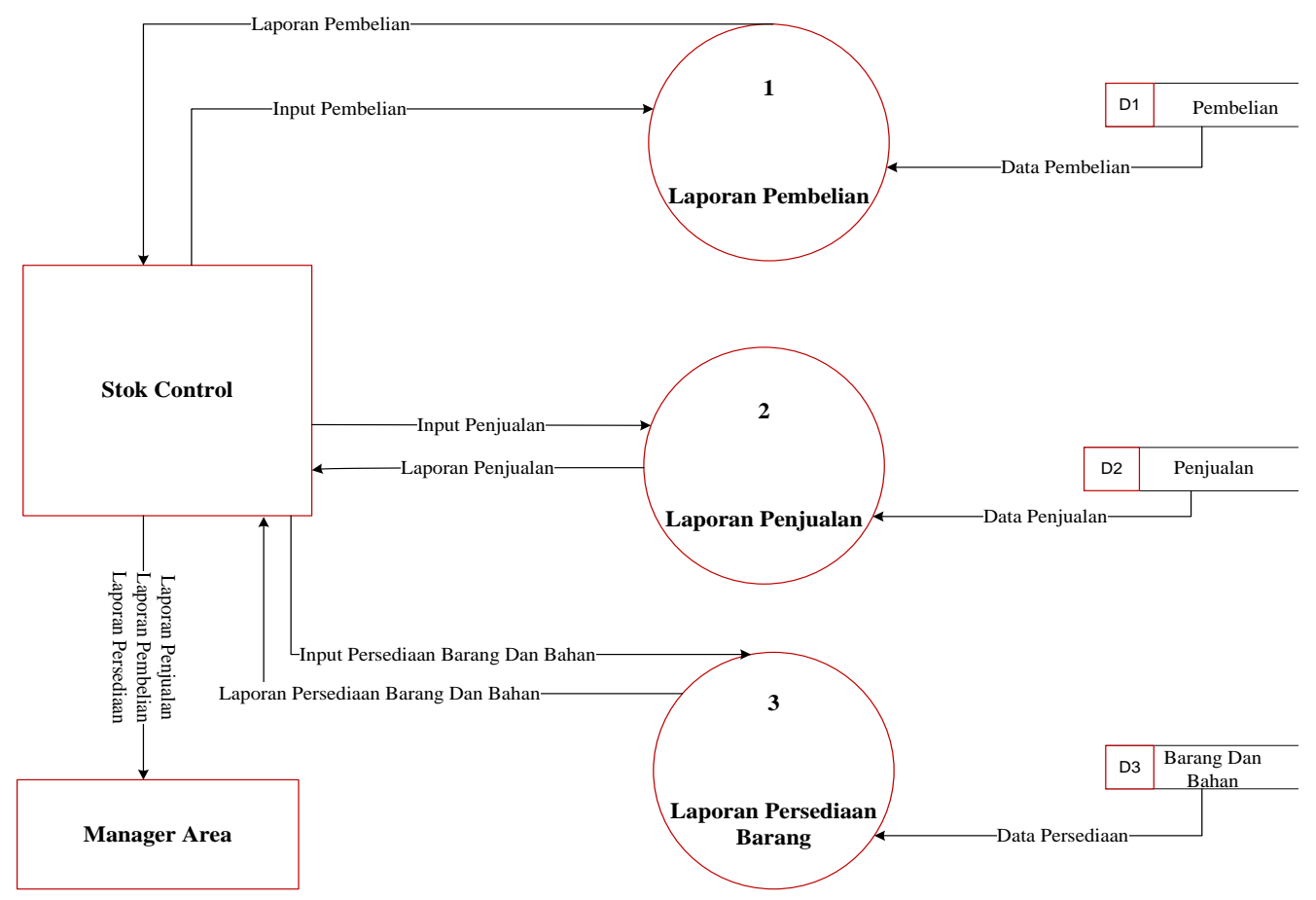

Gambar 3. DFD level 1 pembuatan laporan

Gambar diatas menjelaskan bahwa setiap laporan pembelian, laporan penjualan, dan laporan persediaan barang berasal dari penginputan stok kontrol dan otomatis menuju stok kontrol yang menghasilkan laporan mentah. Setelah penginputan laporan stok kontrol tersebut dilaporkan kepada manager untuk menyesuaikan stok sesuai dengan barang keluar atau barang masuk.

\subsection{Relasi Antar Tabel (RAT)}

Perancangan basis data Sistem Persediaan Barang dan Bahan Makanan Fast Food Indonesai Tbk, Cabang Pematangsiantar disusun berdasarkan hasil observasi dan wawancara sesuai kebutuhan pengguna dalam hal ini pihak pemilik maupun karyawan. Adapun hasil rancangannya dapat dilihat pada gambar 2.

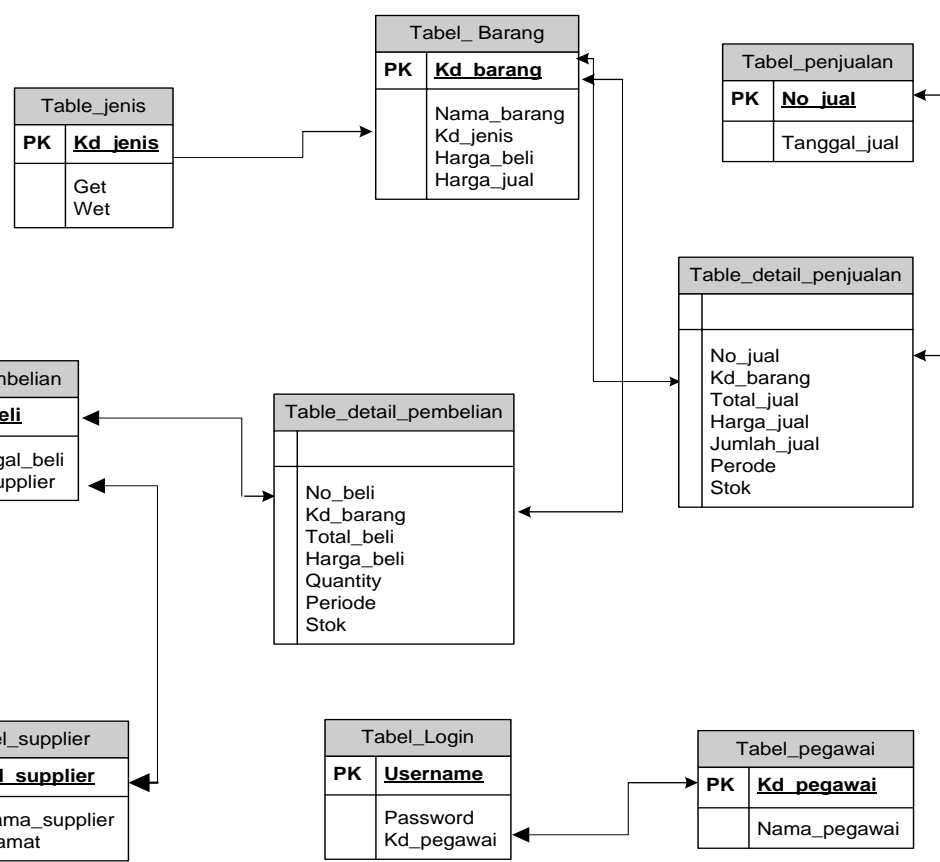

Gambar 4. Relasi Antar Tabel 
Relasi antar tabel dibuat untuk mengetahui hubungan yang terjadi pada data yang disajikan. Pertama login dengan memasukan user dan password yang telah ditentukan pada tabel pegawai. Masuk pada tabel jenis kemudian tabel jenis berelasi dengan tabel barang dan seterusnya saling hubungan/relasi terjadi karena pada tabel 1 dan tabel selanjutnya memiliki field yang sama.

\subsection{Entity Relationship Diagram}

Perancangan basis data dimulai denganmelakukan pengumpulan data kemudian dilakukan perancangan konsep. Entity Relationship Diagram ( ERD ) merupakan diagram yang menyajikan data dan hubungan antar data yang diperlukan oleh aplikasi. Adapun entity relationship digram dari sistem usulan ini sebagai berikut:

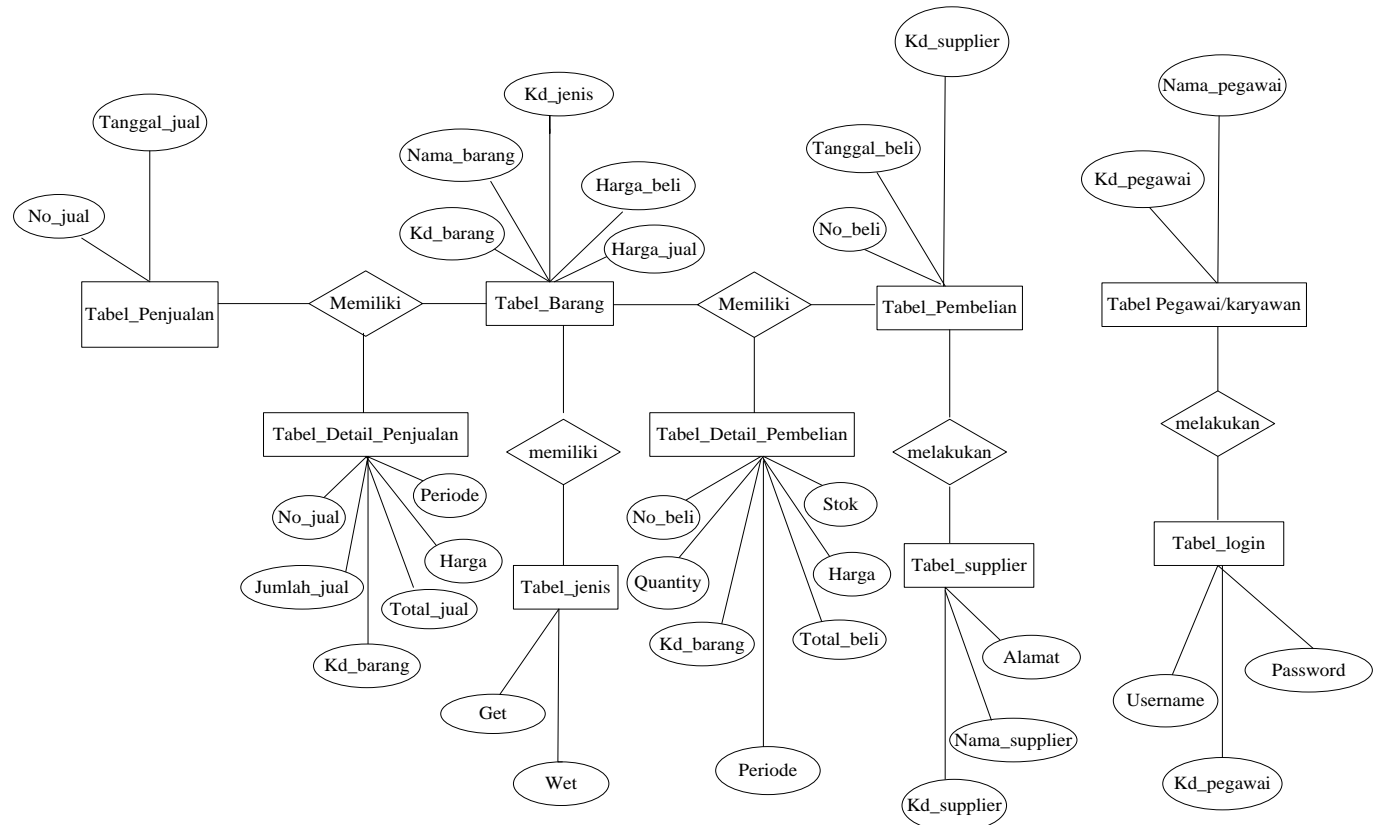

Gambar 5. Entity Relationship Diagram

\subsection{Desain Antar Muka}

1. Menu Login

Form Login berfungsi sebagai kunci untuk pengamanan sistem agar tidak sembarang user dapat mengakses program, seperti pada gambar 6.

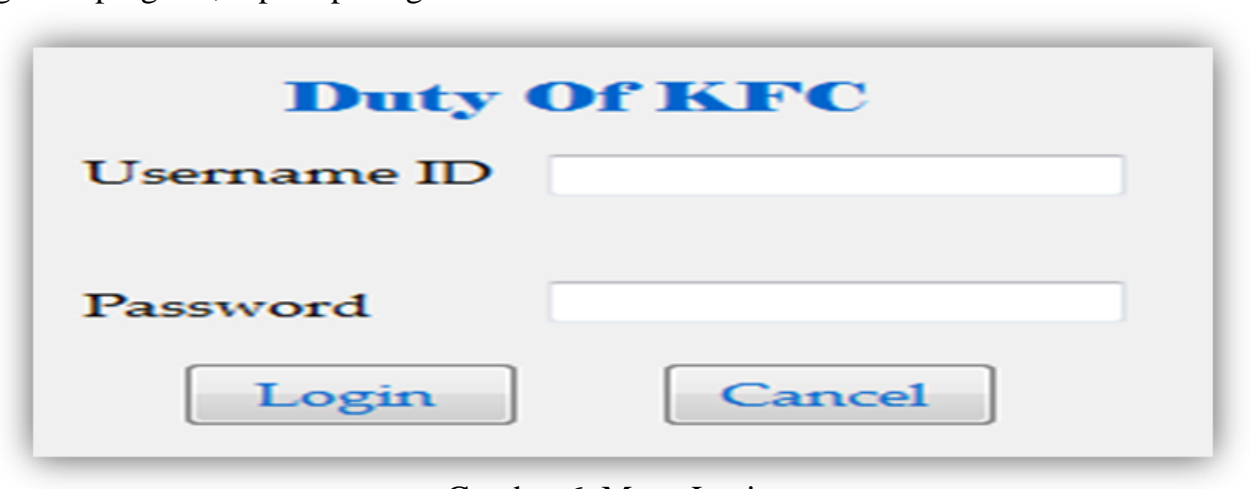

Gambar 6. Menu Login

\section{2. Мепu Utama}

Pada form utama ini berisi menu - menu utama yang dapat dibuka oleh user. Pada form utama ini akan ditampilkan sub menu barang kering dan basah sesuai yang kita inginkan. Tampilan - tampilan halaman utama dapat dilihat pada gambar 7. 


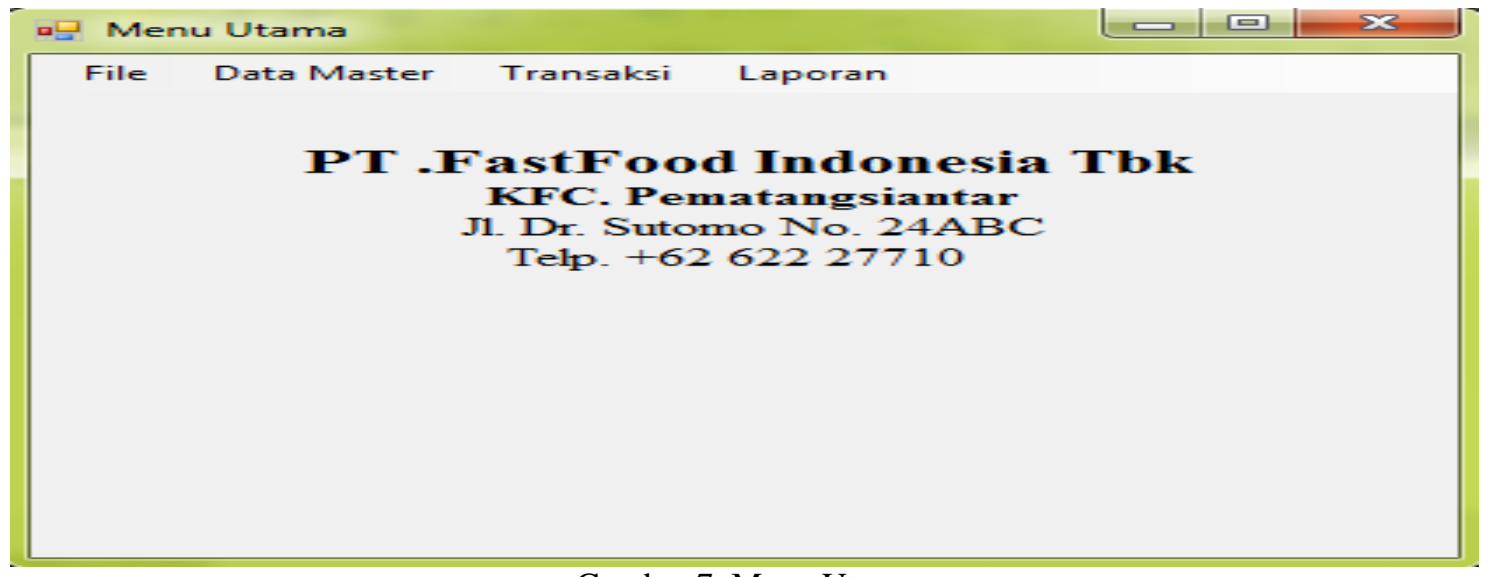

Gambar 7. Menu Utama

3. Menu Master

Menu master digunakan untuk memasukkan data barang, supplier, dan data user sistem ini sesuai pilihan submenunya.

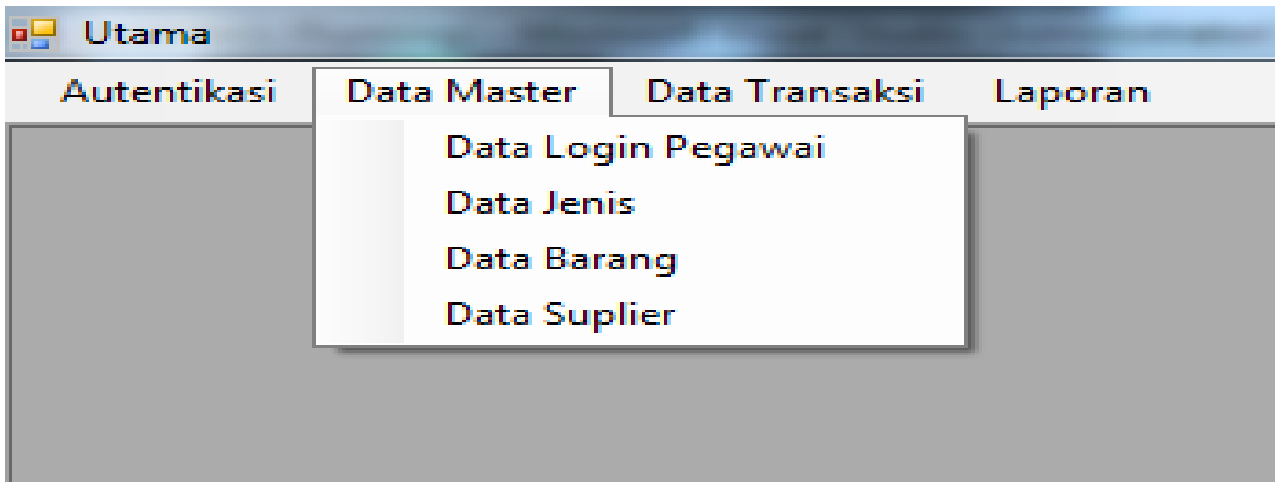

Gambar 8. Menu Master

4. Transaksi

Menu transaksi terdiri dari submenu transaksi Pembelian dan Penjualan.

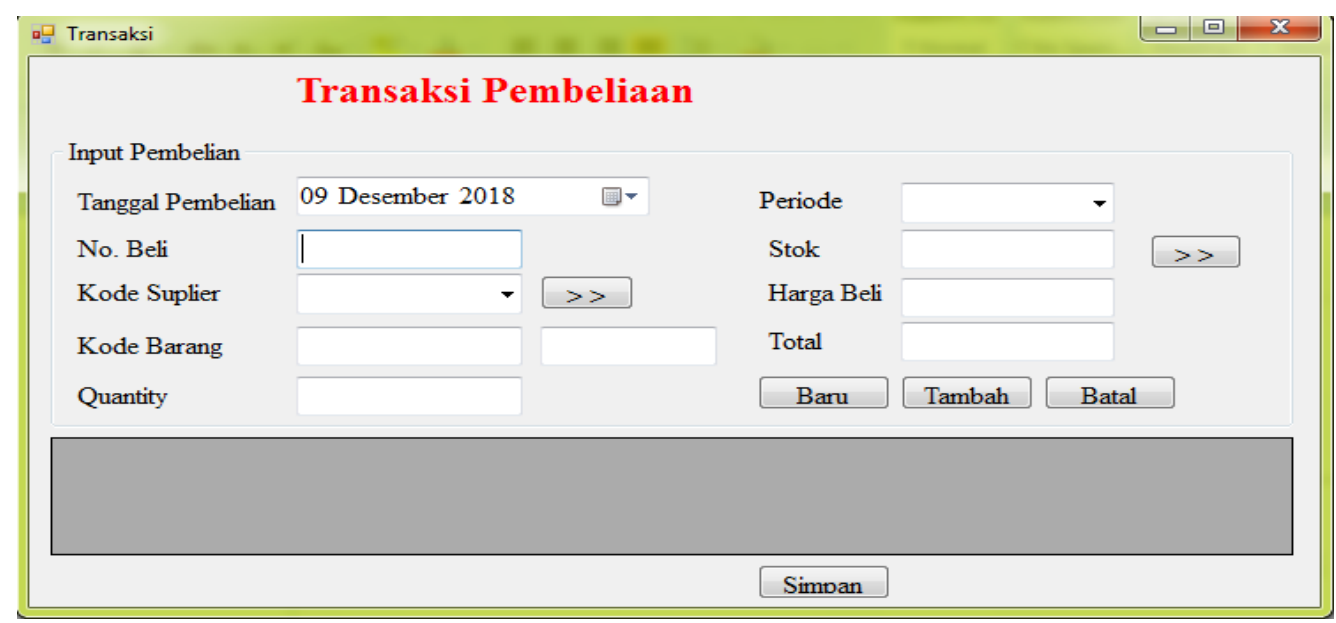

Gambar 9. Transaksi Pembelian 


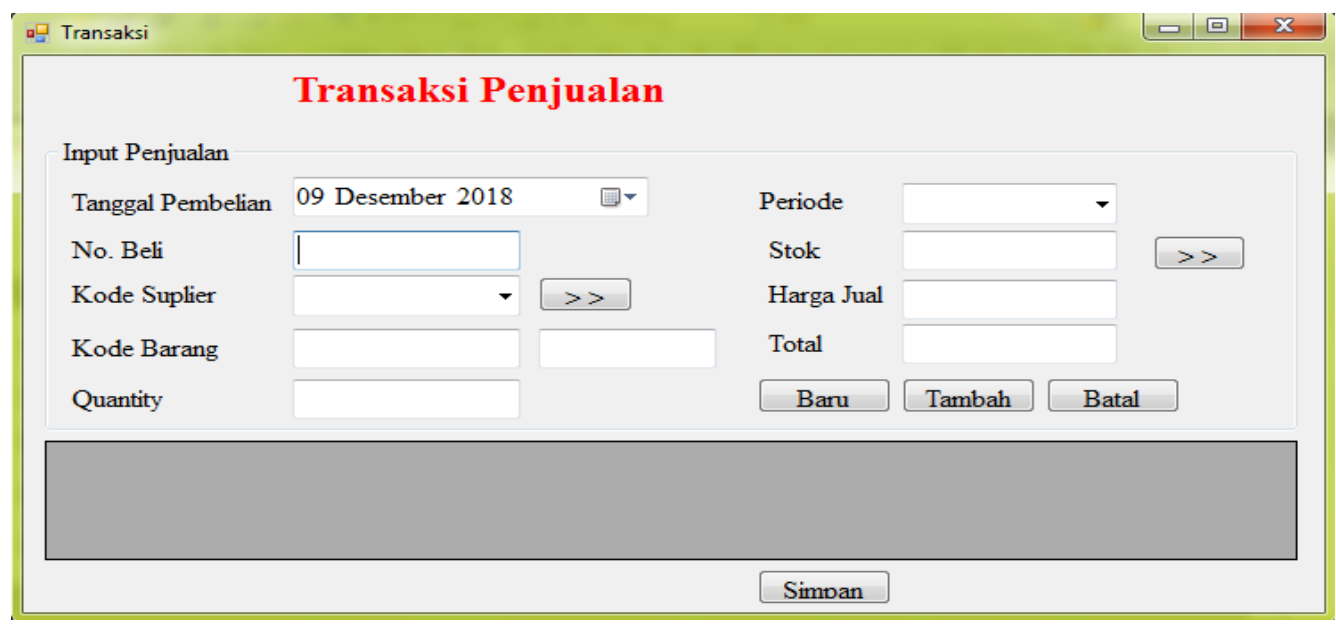

Gambar 10. Transaksi Penjualan

5. Rancangan Keluaran (Output)

Rancangan keluaran merupakan rancangan laporan yang akan dihasilkan oleh sistem yang dirancang. Dibawah ini adalah gambaran dari rancangan keluaran (Output) PT Fast Food Indonesia Tbk, KFC. Pematangsiantar. Adapun rancangan keluaran (Output) adalah sebagai berikut:

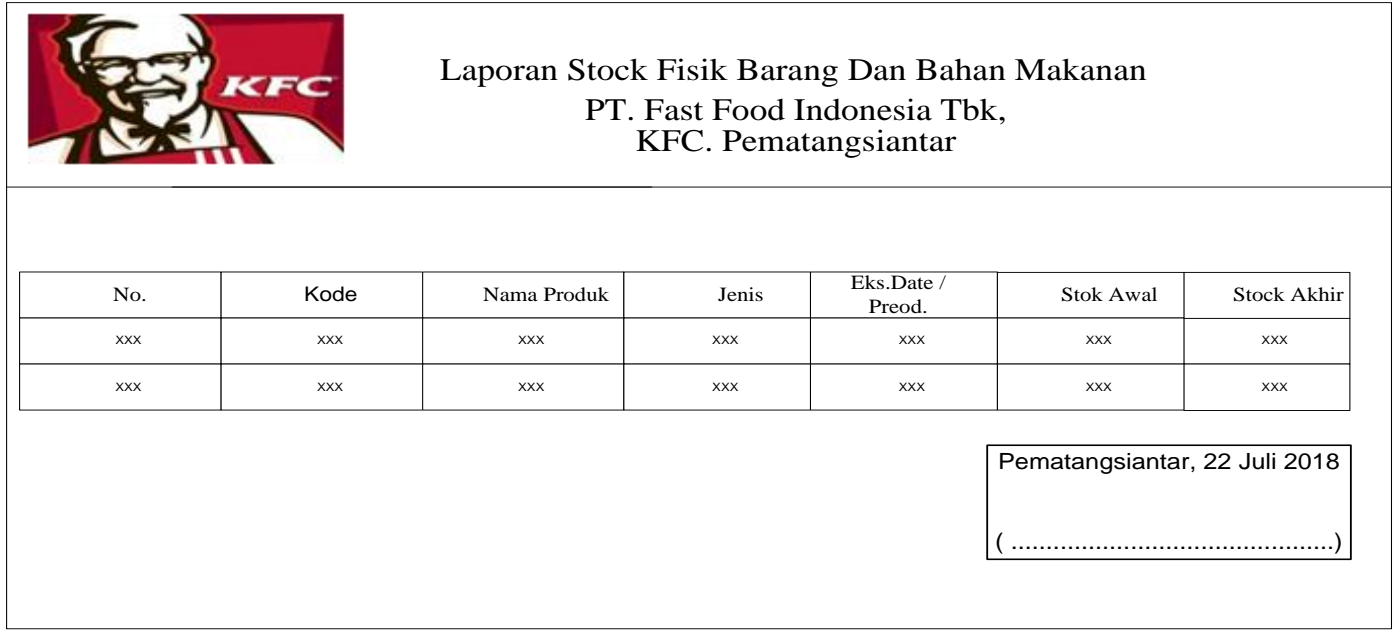

Gambar 11. Rancangan Keluaran

\section{Kesimpulan}

5.1 Simpulan

Dari uraian dan pembahasan sebelumnya, dapat ditarik simpulan aplikasi pada KFC. Pematangsiantar yang dibuat dapat membantu manager maupun karyawan menghasilkan output berupa laporan persediaan barang dan barang makanan secara tepat dan dalam waktu singkat sehingga dapat digunakan oleh karyawan sebagai acuan untuk mengambil keputusan.

\subsection{Saran}

Saran pengembangan aplikasi ke depan adalah masih perlunya pembuatan laporan persediaan barang yang lebih detil agar dapat lebih melihat arus barang dan bahan makanan sesuai metode FIFO.

\section{Daftar Rujukan}

[1] R. Sifa Fauziah, "Penerapan Metode FIFO Pada Sistem Informasi Persediaan Barang," J. Tek. Komput., vol. 4, no. 1, pp. 98-108, 2018.

[2] D. Suhendro, "Analisis Perbandingan Kinerja Keuangan Bank Umum Syariah VS Bank Umum 
Konvensional di Indonesia dengan Menggunakan Rasio Keuangan,” Masharif al Syariah J. Ekon. dan Perbank. Syariah, vol. 3, no. 1, 2018.

[3] D. Wahyudi, "Model Pengelolaan Data Dosen Berbasis Komputer (Studi Kasus pada Politeknik LP3I Medan)," J. Teknovasi, vol. 04, no. 2, pp. 15-19, 2018.

[4] D. Suhendro, "Analisis Penilaian Kinerja Keuangan Perusahaan Menggunakan Rasio Keuangan Pada PT Unilever Indonesia Tbk yang Terdaftar di Bursa Efek Indonesia (BEI)," At-Tawassuth, vol. III, no. I, pp. 482- 506, 2018.

[5] R. R. A. Sitti Nurnaluri, Ishak Awaluddin, "Pengaruh Informasi Akuntansi dalam Pengambilan Kebijakan Keuangan Pemerintah Daerah (Studi pada Pemerintah Kota Kendari)," J. Akunt. dan Keuang. Vol., vol. III, no. 1, pp. 83-98, 2018.

[6] D. Ritonga and O. H. K. James A. Timboeleng, "Analisa Biaya Transportasi Angkutan Umum dalam Kota Manado Akibat Kemacetan Lalu Lintas (Studi Kasus: Angkutan Umum Trayek Pusat Kota 45-Malalayang)," J. Sipil Statik, vol. 3, no. 1, pp. 58-67, 2015.

[7] M. Z. N. Indra Hidayatulloh, "Metode MOORA dengan Pendekatan Price-Quality Ratio untuk Rekomendasi Pemilihan Smartphone," in Proceeding SINTAK, 2017, no. November, pp. 62-68.

[8] D. Meisak, "Analisis dan Perancangan Sistem Informasi Persediaan Barang Menggunakan Metode FIFO pada PT. Shukaku Jambi,” MEDIASISFO, vol. 11, no. 2, pp. 862-875, 2017.

[9] D. I. Sari, "Analisis Perhitungan Persediaan dengan Metode FIFO dan Average Pada PT . Harapan," Perspektif, vol. XVI, no. 1, pp. 31-38, 2018.

[10] S. A. Solekha, J. Pramono, S. Rihastuti, J. Veteran, N. Singopuran, and K. Sukoharjo, "Komputerisasi Penilaian Persediaan Barang Dagang dengan Metode FIFO pada Distro Wallnut Invansion Boyolali," J. EKA CIDA, vol. 2, no. 1, pp. 21-29, 2017. 